\title{
Urological issues in pregnancy: A review for urologists
}

Joshua White ${ }^{1}$; Jesse Ory ${ }^{1}$; Andrea G. Lantz Powers ${ }^{1}$; Michael Ordon ${ }^{2}$; Jamie Kroft ${ }^{3}$; Ashley $\operatorname{Cox}^{1}$

${ }^{1}$ Department of Urology, Dalhousie University, Halifax, NS, Canada; ${ }^{2}$ Division of Urology, University of Toronto, Toronto, ON, Canada; ${ }^{3}$ Department of Obstetrics and Gynecology, University of Toronto, Toronto, ON, Canada

Cite as: Can Urol Assoc J 2020 May 12; Epub ahead of print. http://dx.doi.org/10.5489/cuaj.6526

Published online May 12, 2020

$* * *$

\begin{abstract}
Urological issues in the pregnant patient present a unique clinical dilemma. These patients may be challenging to treat due to risks associated with medications and surgical procedures. This review aims to provide an update on the physiological changes and surgical risks in pregnancy. In addition, we review the approach for management of urolithiasis and urinary tract infections (UTIs) in pregnancy. Lastly, we highlight the importance of a multidisciplinary approach to placenta percreta, a condition not commonly addressed in urological education.
\end{abstract}




\section{Introduction}

Pregnant patients presenting with urological complaints can often be a challenging population to treat. There is a paucity of high-quality literature to guide management and the risks of inappropriate treatment may have serious consequences for both the fetus and mother. We reviewed the literature for common urological presentations in pregnancy and present a review of the literature to help guide clinical decision-making.

\section{Physiology in pregnancy}

There are important physiological changes in pregnancy that urologists must consider. Physiologic hydronephrosis is commonly observed, particularly on the right side; $50-90 \%$ of patients may have hydronephrosis by the third trimester. ${ }^{1,2}$ Dilatation develops primarily in the second and third trimester where the ureters cross the pelvic brim, and so the dilatation tends to be seen proximal to this. ${ }^{3}$ This is partially due to hypertrophy of Waldeyer's sheath, the external longitudinal muscle layer in the distal ureter. ${ }^{4,5}$ In addition, progesterone reduces ureteric tone, thereby reducing peristalsis and contraction pressure. ${ }^{6}$ Right-sided hydronephrosis is more commonly observed as compared to left-sided, as a result of several factors. First, the ovarian vein on the right crosses over the ureter before entering the inferior vena cava, whereas the left ovarian vein runs parallel to the ureter before entering the renal vein. ${ }^{7}$ Second, the uterus is dextrorotated and lastly the left ureter is protected by the gas-filled sigmoid colon. ${ }^{8}$

Physiological changes may also influence stone formation. The capacity of the collecting system increases by an estimated $200-300 \mathrm{~mL}$, leading to urinary stasis. ${ }^{9}$ An increased excretion of sodium, calcium and uric acid due to increased glomerular filtration rate is observed. ${ }^{9}$ These factors may increase the patient's propensity to form stones. ${ }^{10}$ Conversely, increased urine alkalinity, renal blood flow and excretion of urinary citrate, magnesium and nephrocalcin may inhibit stone formation. ${ }^{10-12}$ This leads to no overall change in the incidence of nephrolithiasis in pregnancy compared to the general population. Yet, the rate of stent and nephrostomy tube encrustation is higher in pregnancy, possibly due to urinary stasis and the increase in urinary calcium excretion. ${ }^{13}$

\section{Surgical risk in pregnancy}

The most common indication for urological surgery in the pregnant patient is symptomatic urolithiasis. $^{13,14}$ The American College of Obstetricians and Gynecologists (ACOG) in conjunction with the American Society of Anesthesiologists (ASA) published recommendations for non-obstetrical surgery during pregnancy. ${ }^{15}$ Important for the urologist to consider are the following points: a) A pregnant woman should never be denied medically necessary surgery or have that surgery delayed regardless of trimester because this can adversely affect the pregnant woman and her fetus and, b) Elective surgery should be postponed until after delivery. ${ }^{15}$ A third recommendation, present in the 2017 ACOG guideline is absent in the 2019 opinion: to perform non-urgent surgery in the second trimester. This recommendation was largely based on poor quality data, and has since been removed. ${ }^{16}$ 
The urologist should approach surgery in the obstetrical patient in a multidisciplinary fashion. When possible, surgery should be performed in a centre with neonatal and pediatric services ${ }^{15}$ if the fetus is beyond viability ( 22 weeks gestational age). ${ }^{17}$ Obstetrics should be notified if surgery is planned and peri/intra-operative monitoring coordinated when appropriate. ${ }^{15}$

\section{Urolithiasis in pregnancy}

The incidence of symptomatic urolithiasis in pregnant patients is equal to nonpregnant women of childbearing age, estimated to be between $0.03-0.53 \% .{ }^{18-21}$ The largest and most recent population-based study from Ontario, Canada, demonstrated an incidence of $0.2 \%$ for symptomatic stones in pregnancy between 2004-2014. ${ }^{22}$ Kidney stones in pregnancy have been associated with an increased risk of preterm birth, low birth weight, pre-eclampsia, caesarian section, premature rupture of membranes and preterm delivery in various studies. ${ }^{22-23,24}$ Diagnosis of urolithiasis in pregnancy can be challenging as common symptoms and findings often occur in the setting of pregnancy independent of urolithiasis. One retrospective review found that most clinical signs and symptoms were not helpful in distinguishing urolithiasis and physiological hydronephrosis. ${ }^{25}$ Left-sided flank pain, microscopic hematuria and a prior history of stones were reported as statistically significant predictors of urolithiasis. ${ }^{25}$

The American Urological Association (AUA), European Association of Urological (EAU) and American College of Radiology (ACR) recommend ultrasound as the first-line imaging study in pregnant patients ${ }^{26-28}$. Unfortunately, ultrasound is only $34 \%$ sensitive for ureteric stones in this population. ${ }^{25}$ Adjuncts such as a reduced or absent ureteric jet coupled with an elevated renal resistive index (RI) or an elevated RI alone have been shown to improve ultrasound accuracy between 71.9 and $77 \%{ }^{25,29}$ The RI is defined as the peak diastolic velocity subtracted from the peak systolic velocity, divided by the peak systolic velocity. ${ }^{29}$ False positives may occur due to compression of the ureter by the uterus when assessing ureteric jets with colour Doppler. Therefore, the test should be repeated in the contralateral decubitus position. ${ }^{30}$

Urolithiasis is one of the most common causes of non-obstetrical admission in the gravid patient. ${ }^{31}$ Conservative management with IV fluids and analgesia is recommended as a first step for suitable patients. ${ }^{32}$ Likely as a result of the increased ureteric dilation, spontaneous passage rates for kidney stones $<1 \mathrm{~cm}$ during pregnancy range from $70-80 \%$, with nearly half of remaining stones passing spontaneously in the postpartum period. ${ }^{23,24,33-37}$ With that being said, one study of 144 pregnant patients with urolithiasis found that a disproportionally low percentage of UPJ stones passed spontaneously $(27.3 \%)$. ${ }^{25}$ Patients that require more aggressive management include patients with refractory pain, bilateral obstruction, obstruction in a solitary kidney and obstruction with urinary tract infection (UTI) or sepsis. ${ }^{13}$

The use of alpha-blockers for medical expulsive therapy (MET) for ureteric stones is controversial, even in non-pregnant patients. In appropriately selected non-pregnant patients, (i.e. distal stones $>5 \mathrm{~mm}$ ), MET may be advocated for the passage of ureteric stones. ${ }^{38}$ Use of alpha- 
blockers for MET is "off-label" with the proposed benefit of smooth muscle relaxation of the ureters to facilitate stone passage. ${ }^{39}$ Urologists must question the utility of such medications in pregnancy given that increased progesterone in pregnancy has an effect of smooth muscle relaxation. ${ }^{6,32}$ A number of small retrospective studies evaluating MET in pregnant women have found that MET is not associated with statistically significant maternal or fetal outcomes. ${ }^{40,41}$ One of these studies identified two cases of sudden infant death syndrome in the MET group compared with none in the conservative management group, though this failed to reach statistical significance. ${ }^{40}$ There is a paucity of high-quality evidence to support the efficacy of MET in pregnant patients. One meta-analysis of the effects of alpha blockers and antimuscarinics used alone or in combination therapy to relieve stent-related symptoms found that the efficacy and appropriateness in pregnant patients is unclear. ${ }^{42}$

Temporization with ureteric stents and/or percutaneous nephrostomy tubes has been widely used in pregnant patients with obstructing stones. This may be performed under local anesthetic or sedation. Indwelling stents may be poorly tolerated, however, and are at a high risk of bacterial colonization and encrustation. ${ }^{43}$ Stent encrustation can result in obstruction requiring further surgical management, and as such stents require exchange every 4-6 weeks in pregnant patients. ${ }^{31,43,44}$ Placement of nephrostomy tubes has been shown to be safe in numerous studies, though they come with similar limitations as stents. ${ }^{45,46}$

Advances in endourology have improved the safety and efficacy of ureteroscopic management of stones in pregnancy. ${ }^{14}$ Spinal anesthetic may be used for the treatment of distal stones. ${ }^{47}$ Ureteroscopy is a safe form of treatment in the pregnant patient as demonstrated in a 2012 systematic review. Eight-six percent (100/116, 86\%) of procedures resulted in stone clearance with a serious complication rate of only $1.6 \%$ (1 ureteric perforation, 1 case of premature uterine contractions which resolved without progressing to preterm labor). ${ }^{48}$ No adverse fetal outcomes were observed. Intraoperative complications were rare and post-operative complications occurred in approximately $8 \%$ of patients. ${ }^{48}$ Post-operative complications were all Clavien grade II or less (UTI; $4.3 \%(n=5)$, stent-related pain: $1.7 \%(n=2)$. Five obstetrical complications were found in a case series of 378 patients, which included premature uterine contractions, pre-term labor and pre-term delivery. ${ }^{48}$ Multiple large observational trials have also been conducted and have shown that while the presence of symptomatic stones increases the risk of preterm labor, performing ureteroscopy was not found to increase that risk. ${ }^{23,49,50}$ The largest of these was a retrospective cohort study identifying 2239 women admitted for nephrolithiasis. In this review, they found that the odds of preterm birth was 1.72 in patients with stones that did not undergo intervention. ${ }^{23}$ Conversely, the odds of preterm birth was 1.69 in patients with stones who had a procedure. ${ }^{23}$ There were no maternal or fetal deaths described. Contrary to these findings a recent population-based study demonstrated, as part of a secondary analysis, a small increased risk of adverse birth outcome in those pregnancies undergoing ureteroscopy for kidney stones (OR 1.82, 95\% CI 1.34--2.47) as compared to matched control pregnancies with stones 
and no intervention (OR 1.20, 95\%CI 1.04-1.39). ${ }^{22}$ Specifically, ureteroscopy was associated with increased risk of preterm birth and caesarian section ${ }^{22}$.

There is scarce literature to guide the decision to place stents post-operatively. One case series $(n=7)$ found pregnant patients undergoing ureteroscopy were more likely to return to hospital with colic if stents were not placed. ${ }^{51}$ Another case series $(n=26)$ found no difference in pregnancy outcomes between stented and unstented patients post ureteroscopy. ${ }^{43}$

Extracorporeal shockwave lithotripsy (ESWL) is absolutely contraindicated in pregnancy due to fetal death and malformations observed in animal studies. ${ }^{52,53}$ Percutaneous nephrolithotomy (PCNL) is considered contraindicated in the pregnant patient due to the need for general anesthetic, patient positioning, and prolonged need for fluoroscopy. ${ }^{54}$ There are case reports of PCNL being performed safely in all three trimesters, but there is not enough literature to recommend PCNL outside of an experimental setting. ${ }^{54-56}$

\section{Urinary tract infections in pregnancy}

Asymptomatic bacteriuria occurs in $2-15 \%$ of pregnant women. ${ }^{57}$ Lower urinary tract infections, regardless of symptoms, are associated with a 20-30\% increase in developing pyelonephritis in pregnancy. ${ }^{58}$ Acute pyelonephritis is one of the leading causes of nonobstetric antepartum hospitalization. ${ }^{59}$ Pregnant patients with asymptomatic bacteriuria require treatment to reduce the risk of ascending infections and pyelonephritis. ${ }^{60,61}$ Ascending infections and pyelonephritis are associated with poor maternal and fetal outcomes, including: maternal sepsis, maternal hypertension, preeclampsia, preterm birth, low birthweight, intrauterine growth retardation (IUGR), acute respiratory distress syndrome (ARDS), preterm rupture of membranes, and perinatal death. ${ }^{61-64}$ Preterm birth is the primary contributor to fetal morbidity and mortality. ${ }^{65}$ Pyelonephritis may result in preterm birth in $20-50 \%$ of cases. ${ }^{57}$ The exact incidence of symptomatic UTI in pregnant women is unknown, though it is estimated to be between $1 \%$ and $2.3 \%{ }^{66,67} \mathrm{E}$. coli is the most common pathogen, isolated in nearly $90 \%$ of specimens. ${ }^{68} \mathrm{~A}$ Cochrane review found no difference in rates of pyelonephritis or recurrent urinary tract infections for patients taking daily low-dose prophylactic antibiotics vs. placebo. ${ }^{69}$

Antimicrobials should be selected wisely and based on culture results when feasible. Antibiotics commonly used in pregnancy include penicillin and first generation cephalosporins. ${ }^{70}$ Penicillins, erythromycins and cephalosporins are not associated with an increased risk of birth defects, and their use is advocated for by the American College of Obstetricians and Gynecologists (ACOG). ${ }^{71}$ Tetracyclines lead to fetal dental staining. ${ }^{72}$ Quinolones have been shown to damage cartilage when used in pregnant dogs and should be avoided. ${ }^{73}$ Macrolides, particularly during the first trimester, have been shown consistently to increase the risk of miscarriage, and there is uncertainty regarding increased risks of cerebral palsy and epilepsy. ${ }^{74}$ Trimethoprim interferes with folate metabolism and exposure in the first trimester is associated with a risk of miscarriage. ${ }^{75}$ The ACOG considers sulfonamides and nitrofurantoin to be appropriate for use in the first trimester when there are no suitable alternatives. ${ }^{71}$ Their use is 
appropriate as first-line agents in the second and third trimester. ${ }^{71}$ An important clinical caveat is that the use of sulfonamides and nitrofurantoin are contraindicated in patients with glucose-6phosphate dehydrogenase deficiency, or those that may be at risk of having it due to the risk of jaundice and hemolytic anemia. ${ }^{71}$

\section{Radiation safety in pregnancy}

Due to concerns regarding harms of ionizing radiation, the overarching principle of medical radiation management is to keep radiation levels "as low as reasonably achievable" (ALARA) for all patients. ${ }^{80}$ Ionizing radiation can be viewed as having both stochastic and deterministic effects. Deterministic effects have a predictable dose dependent effect, and early effects, such as acute radiation sickness are considered deterministic. ${ }^{81}$ Chromosomal damage and malignancy tend to be considered stochastic effects, which follow a linear no threshold model. ${ }^{80,81}$ The linear no threshold model suggests that the risk of malignancy increases in a linear manner and that even the smallest dose has the potential to increase the risk of malignancy. ${ }^{82}$ It is important for the urologist to familiarize themselves with these risks in order to appropriately counsel pregnant patients in the evaluation and management of urolithiasis. Deterministic effects tend to be measured by the absorbed dose in Gray, whereas stochastic effects tend to be measured by the equivalent dose in Sieverts. ${ }^{83}$

Radiation risks to the fetus have been extensively researched, though there are several uncertainties that still exist. Evidence used to determine the risks associated with ionizing radiation come primarily from case-control studies and evidence from survivors of the atomic bombs in Hiroshima and Nagasaki. A large case control study from 1970 examined the children of mothers who received ionizing radiation. They found that doses on the order of $10 \mathrm{mGy}$ led to the rate of leukemia increasing from a background rate of $0.2-0.3 \%$ to approximately $0.3-0.7 \%{ }^{84}$ Furthermore, the study later found that embryos were more sensitive to the lethal effects of radiation than more mature fetuses. ${ }^{85}$ Another study of 1300 adults exposed in utero during the atomic bomb explosions found no increased cancer risk under $100 \mathrm{mGy} .{ }^{86}$ Another similar study of 2452 adults found no increased cancer risk under $200 \mathrm{mGy} .{ }^{87}$ To be safe, the most conservative estimates are used to ensure the safety of the fetus. Multiple national and international organizations suggest that the accepted safe cumulative dose to the fetus during pregnancy should be no more than $50 \mathrm{mGy}$, and that $10-20 \mathrm{mGy}$ is estimated to increase leukemia risk by $1.5-2.0$ over a background rate of 1 in $3000 .{ }^{88-90}$

When considering kidney stones in pregnancy, the risks of ionizing radiation need to be balanced against the risk of a negative ureteroscopy due to uncertainty in the diagnosis of obstructing stones. One trial of 51 women found a negative ureteroscopy rate of only $4.2 \%$ in women who received ultrasound and CT scan, compared to a negative ureteroscopy rate of 20 and $23 \%$ in those who received MRI alone and Ultrasound alone, respectively. ${ }^{91}$ 


\section{Placenta percreta with invasion into urinary bladder}

Placenta accreta is an abnormal adherence of the placenta to the myometrium, placenta increta is invasion of the placenta into the myometrium and placenta percreta has invasion through to serosa and adjacent structures, such as the bladder. ${ }^{92}$ The exact incidence of placenta percreta is unclear, though appears to be more common as rates of caesarean delivery have increased and is estimated as 1 in 500 in developed countries. ${ }^{93}$ The most important risk factor for placenta percreta is the observation of placenta previa in a subsequent pregnancy, following a previous cesarean delivery. ${ }^{94}$ Severe hemorrhage may occur, resulting in maternal and/or fetal demise..$^{95}$ One meta-analysis found maternal and fetal fatality rates of $6 \%$ and $19 \%$, respectively. ${ }^{96}$ Early diagnosis with US or MRI is critical. Hematuria may occur in $25 \%$ of cases with bladder involvement, through frequently patients are asymptomatic. ${ }^{94}$

A case series $(n=54)$ of placenta percreta invading the urinary bladder found a significant risk of serious complications as $38.9 \%$ of patients required partial cystectomy and/or hysterectomy. ${ }^{96}$ Partial cystectomy increased the risk of vesicovaginal fistula and need for further intervention. Seventy-two percent of patients developed early or late urological complications requiring further surgical intervention.

Urological consultation is recommended before a scheduled delivery, as it has been associated with a decreased incidence of urological complications. ${ }^{97,98}$ Preoperative ureteral stent placement has been shown to decrease the incidence of ureteral injury during cesarean hysterectomy in placenta percreta. ${ }^{99}$ Biopsies of atypical bladder mucosa during cystoscopy should be avoided as they may significantly increase risk of hemorrhage. ${ }^{96}$ Anterior bladder wall cystotomy has been demonstrated to be of benefit to help determine if posterior bladder wall resection is necessary. ${ }^{100}$ It is also essential for the urologist to know that attempts to dissect through placenta to save bladder wall is likely to result in massive hemorrhage and should be avoided. $^{95}$

\section{Conclusions}

Pregnant patients may present with urological problems that necessitate management. Concerns over maternofetal safety are paramount and add a layer of complexity in the urologists approach to treatment. It is important to understand the physiological changes associated with pregnancy and to familiarize ones' self with the risks and benefits of management strategies in order to provide the highest level of care to this population. A multidisciplinary approach is advised, ensuring the patient's obstetrician is informed of urological interventions planned. 


\section{References}

1. Pedro RN, Das K and Buchholz N: Urolithiasis in pregnancy. Int. J. Surg. 2016; 36: 688-692.

2. Grosjean J, Cannie M and de Meyer J-M: Physiological hydronephrosis in pregnancy: Occurrence and possible causes. An MRI study. Edited by J Grosjean. Progres En Urol. J. Assoc. Francaise Urol. Soc. Francaise Urol. 2017; 27: 603-608.

3. Rasmussen PE and Nielsen FR: Hydronephrosis during pregnancy: a literature survey. Eur. J. Obstet. Gynecol. Reprod. Biol. 1988; 27: 249-259.

4. Muellner S. Richard: Physiological Bladder Changes during Pregnancy and the Puerperium1. J. Urol. 1939; 41: 691-695.

5. Anon: Hinman's atlas of urosurgical anatomy, $2 \mathrm{~d}$ ed. (online access included). Ref. Res. Book News 2012; 27.

6. Swift S and Ostergard D: Effects of progesterone on the urinary tract. Pelvic Floor Dysfunct. 1993; 4: 232-236.

7. Shah MS and Tozzo PJ: Right ovarian vein syndrome. Urology $1974 ; 3$ : 488-490.

8. Bres-Niewada E: Ureteral obstruction in pregnancy - The "Stone Mountain" for the Urologist. Cent. Eur. J. Urol. 2017; 70: 101-102.

9. Mandal D, Saha M and Pal D: Urological disorders and pregnancy: An overall experience. Urol. Ann. 2017; 9: 32-36.

10. Maikranz P, Coe FL, Parks J, et al: Nephrolithiasis in pregnancy. Am. J. Kidney Dis. Off. J. Natl. Kidney Found. 1987; 9: 354-358.

11. Ross AE, Handa S, Lingeman JE, et al: Kidney stones during pregnancy: an investigation into stone composition. Urol. Res. 2008; 36: 99-102.

12. Cheung KL and Lafayette RA: Renal physiology of pregnancy. Adv. Chronic Kidney Dis. 2013; 20: 209-214.

13. Martindale AD and Paisley AM: Surgical and urological problems in pregnancy. Curr. Obstet. Gynaecol. 2004; 14: 350-355.

14. Giusti G, Proietti S, Peschechera R, et al: Sky is no limit for ureteroscopy: extending the indications and special circumstances. World J. Urol. 2015; 33: 257-273.

15. Anon: ACOG Committee Opinion No. 775 Summary: Nonobstetric Surgery During Pregnancy. Obstet. Gynecol. 2019; 133: 844-845.

16. Tolcher MC, Fisher WE and Clark SL: Nonobstetric Surgery During Pregnancy. Obstet. Gynecol. 2018; 132: 395-403.

17. Ladhani NNN, Chari RS, Dunn MS, et al: No. 347-Obstetric Management at Borderline Viability. J. Obstet. Gynaecol. Can. 2017; 39: 781-791.

18. Hendricks K Susan, Ross O Susan and Krieger N John: An Algorithm for Diagnosis and Therapy of Management and Complications of Urolithiasis During Pregnancy. Obstet. Gynecol. Surv. 1991; 46: 603-605.

19. Butler EL, Cox SM, Eberts EG, et al: Symptomatic nephrolithiasis complicating pregnancy. Obstet. Gynecol. 2000; 96: 753-756.

20. Masselli G, Derme M, Laghi F, et al: Imaging of stone disease in pregnancy. Abdom. Imaging 2013; 38: 1409-1414. 
21. Semins J Michelle and Matlaga R Brian: Management of stone disease in pregnancy. Curr. Opin. Urol. 2010; 20: 174-177.

22. Ordon M, Dirk J, Slater J, et al: Incidence, Treatment, and Implications of Kidney Stones During Pregnancy: A Matched Population-Based Cohort Study. J. Endourol. 2020.

23. Swartz A Mia, Lydon-Rochelle T Mona, Simon L David, et al: Admission for Nephrolithiasis in Pregnancy and Risk of Adverse Birth Outcomes. Obstet. Gynecol. 2007; 109: 1099-1104.

24. Lewis F David, Robichaux G Alfred, Jaekle K Ronald, et al: Urolithiasis in Pregnancy: Diagnosis, Management, and Pregnancy Outcome. Obstet. Gynecol. Surv. 2003; 58: 446-447.

25. Andreoiu M and Macmahon R: Renal Colic in Pregnancy: Lithiasis or Physiological Hydronephrosis? Urology 2009; 74: 757-761.

26. Coursey CA, Casalino DD, Remer EM, et al: ACR Appropriateness Criteria ${ }^{\circledR}$ acute onset flank pain--suspicion of stone disease. Edited by CA Coursey. Ultrasound Q. 2012; 28: 227-233.

27. Fulgham PF, Assimos DG, Pearle MS, et al: Clinical Effectiveness Protocols for Imaging in the Management of Ureteral Calculous Disease: AUA Technology Assessment. J. Urol. 2013; 189: 1203-1213.

28. Türk C, Petř́k A, Sarica K, et al: EAU Guidelines on Interventional Treatment for Urolithiasis. Eur. Urol. 2016; 69: 475-482.

29. Shokeir AA, Mahran MR and Abdulmaaboud M: Renal colic in pregnant women: role of renal resistive index. Urology 2000; 55: 344-347.

30. Karabulut $\mathrm{N}$ and Karabulut A: Colour Doppler evaluation of ureteral jets in normal second and third trimester pregnancy: effect of patient position. Br. J. Radiol. 2002; 75: 351-355.

31. Valovska M-TI and Pais VM: Contemporary best practice urolithiasis in pregnancy. Ther. Adv. Urol. 2018; 10: 127-138.

32. Assimos D, Krambeck A, Miller NL, et al: Surgical Management of Stones: American Urological Association/Endourological Society Guideline, PART II. J. Urol. 2016; 196: 1161-1169.

33. Drago JR, Rohner TJJ and Chez RA: Management of urinary calculi in pregnancy. Urology 1982; 20: 578-581.

34. Horowitz E and Schmidt JD: Renal calculi in pregnancy. Clin. Obstet. Gynecol. 1985; 28: $324-338$.

35. Stothers L and Lee LM: Renal colic in pregnancy. J. Urol. 1992; 148: 1383-1387.

36. Parulkar BG, Hopkins TB, Wollin MR, et al: Renal colic during pregnancy: a case for conservative treatment. J. Urol. 1998; 159: 365-368.

37. Evans HJ and Wollin TA: The management of urinary calculi in pregnancy. Curr. Opin. Urol. 2001; 11: 379-384.

38. Ye Z, Zeng G, Yang H, et al: Efficacy and Safety of Tamsulosin in Medical Expulsive Therapy for Distal Ureteral Stones with Renal Colic: A Multicenter, Randomized, Double-blind, Placebo-controlled Trial. Eur. Urol. 2018; 73: 385-391. 
39. Lloyd GL, Lim A, Hamoui N, et al: The Use of Medical Expulsive Therapy During Pregnancy: A Worldwide Perspective Among Experts. Edited by GL Lloyd. J. Endourol. 2016; 30: 354-358.

40. Bailey G, Vaughan L, Rose C, et al: Perinatal Outcomes with Tamsulosin Therapy for Symptomatic Urolithiasis. J. Urol. 2016; 195: 99-103.

41. Theriault Benoit, Morin Fannie and Cloutier Jonathan: Medical expulsive therapy in pregnancy: a retrospective study. J. Urol. 2018; 199: e411-e411.

42. Zhou L, Cai X, Li H, et al: Effects of $\alpha$-Blockers, Antimuscarinics, or Combination Therapy in Relieving Ureteral Stent-Related Symptoms: A Meta-Analysis. J. Endourol. 2015; 29: 650 .

43. Rivera ME, Mcalvany KL, Brinton TS, et al: Anesthetic Exposure in the Treatment of Symptomatic Urinary Calculi in Pregnant Women. Urology 2014; 84: 1275-1278.

44. Choi CI, Yu YD and Park DS: Ureteral Stent Insertion in the Management of Renal Colic during Pregnancy. Edited by CI Choi. Chonnam Med. J. 2016; 52: 123-127.

45. Khoo L, Anson K and Patel U: Success and Short-term Complication Rates of Percutaneous Nephrostomy during Pregnancy. J. Vasc. Interv. Radiol. 2004; 15: 14691473.

46. Wein A, Kavoussi L, Partin A, et al: Cambell-Walsh Urology. 11th Edition.

47. Bozkurt Y, Penbegul N, Soylemez H, et al: The efficacy and safety of ureteroscopy for ureteral calculi in pregnancy: our experience in 32 patients. Urolithiasis 2012; 40: 531535.

48. Laing KA, Lam TBL, Mcclinton S, et al: Outcomes of Ureteroscopy for Stone Disease in Pregnancy: Results from a Systematic Review of the Literature. Urol. Int. 2012; 89: 380-386.

49. Zhang S, Liu G, Duo Y, et al: Application of Ureteroscope in Emergency Treatment with Persistent Renal Colic Patients during Pregnancy. PloS One 2016; 11: e0146597.

50. Buttice S, Lagana AS, Vitale SG, et al: Ureteroscopy in pregnant women with complicated colic pain: Is there any risk of premature labor? Arch. Ital. Urol. Androl. Organo Uff. Soc. Ital. Ecogr. Urol. E Nefrol. 2017; 89: 287-292.

51. Akpinar H, Tüfek I, Alici B, et al: Ureteroscopy and holmium laser lithotripsy in pregnancy: stents must be used postoperatively. Edited by H Akpinar. J. Endourol. 2006; 20: 107-110.

52. Streem SB: Contemporary clinical practice of shock wave lithotripsy: a reevaluation of contraindications. J. Urol. 1997; 157: 1197-1203.

53. Smith DP, Graham JB, Prystowsky JB, et al: The effects of ultrasound-guided shock waves during early pregnancy in Sprague-Dawley rats. J. Urol. 1992; 147: 231-234.

54. Somani B, Dellis A, Liatsikos E, et al: Review on diagnosis and management of urolithiasis in pregnancy: an ESUT practical guide for urologists. World J. Urol. 2017; 35: $1637-1649$.

55. Shah A, Chandak P, Tiptaft R, et al: Percutaneous nephrolithotomy in early pregnancy. Int. J. Clin. Pract. 2004; 58: 809-810.

56. Holman E, Toth Cs and Khan MA: Percutaneous Nephrolithotomy in Late Pregnancy. J. Endourol. 1992; 6: 421-424. 
57. Kalinderi K, Delkos D, Kalinderis M, et al: Urinary tract infection during pregnancy: current concepts on a common multifaceted problem. J. Obstet. Gynaecol. J. Inst. Obstet. Gynaecol. 2018; 38: 448-453.

58. Glaser AP and Schaeffer AJ: Urinary Tract Infection and Bacteriuria in Pregnancy. Urol. Clin. North Am. 2015; 42: 547-560.

59. DeYoung TH, Whittington JR, Ennen CS, et al: Pyelonephritis in Pregnancy: Relationship of Fever and Maternal Morbidity. AJP Rep. 2019; 9: e366-e371.

60. Nicolle LE, Bradley S, Colgan R, et al: Infectious Diseases Society of America guidelines for the diagnosis and treatment of asymptomatic bacteriuria in adults. Clin. Infect. Dis. Off. Publ. Infect. Dis. Soc. Am. 2005; 40: 643-654.

61. Gilbert NM, O'Brien VP, Hultgren S, et al: Urinary tract infection as a preventable cause of pregnancy complications: opportunities, challenges, and a global call to action. Glob. Adv. Health Med. 2013; 2: 59-69.

62. Moore A, Doull M, Grad R, et al: Recommendations on screening for asymptomatic bacteriuria in pregnancy. Can. Med. Assoc. J. 2018; 190: E823.

63. Smaill F and Vazquez J: Antibiotics for asymptomatic bacteriuria in pregnancy. Cochrane Database Syst. Rev. 2019. Available at: https://doi.org//10.1002/14651858.CD000490.pub4.

64. Yan L, Jin Y, Hang H, et al: The association between urinary tract infection during pregnancy and preeclampsia: A meta-analysis. Medicine (Baltimore) 2018; 97: e12192e12192.

65. Angelescu K, Nussbaumer-Streit B, Sieben W, et al: Benefits and harms of screening for and treatment of asymptomatic bacteriuria in pregnancy: a systematic review. BMC Pregnancy Childbirth 2016; 16: 336.

66. Mazor-Dray E, Levy A, Schlaeffer F, et al: Maternal urinary tract infection: is it independently associated with adverse pregnancy outcome? J. Matern. Fetal Neonatal Med. 2009; 22: 124-128.

67. Harris RE and Gilstrap LC 3rd: Cystitis during pregnancy: a distinct clinical entity. Obstet. Gynecol. 1981; 57: 578-580.

68. Usta TA, Dogan O, Ates U, et al: Comparison of single-dose and multiple-dose antibiotics for lower urinary tract infection in pregnancy. Int. J. Gynaecol. Obstet. Off. Organ Int. Fed. Gynaecol. Obstet. 2011; 114: 229-233.

69. Schneeberger C, Geerlings SE, Middleton $\mathrm{P}$, et al: Interventions for preventing recurrent urinary tract infection during pregnancy. Cochrane Database Syst. Rev. 2015: CD009279.

70. Sharma AK, Mis FJ, Vo TD, et al: Percutaneous Nephrostomy Tube Placement in Pregnancy: Care of the Mother and Unborn Child. Womens Imaging Interv. 2016; 35 : 85-96.

71. National Library of Medicine: Committee Opinion No. 717 Summary: Sulfonamides, Nitrofurantoin, and Risk of Birth Defects. Obstet. Gynecol. 2017; 130: 666-667.

72. Elder HA, Santamarina BAG, Smith S, et al: The natural history of asymptomatic bacteriuria during pregnancy: The effect of tetracycline on the clinical course and the outcome of pregnancy. Am. J. Obstet. Gynecol. 1971; 111: 441-462.

73. MacLean AB: Urinary tract infection in pregnancy. Int. J. Antimicrob. Agents 2001; 17: $273-277$. 
74. Fan H, Li L, Wijlaars L, et al: Associations between use of macrolide antibiotics during pregnancy and adverse child outcomes. Eur. J. Public Health 2018; 28.

75. Andersen JT, Petersen M, Jimenez-Solem E, et al: Trimethoprim use in early pregnancy and the risk of miscarriage: a register-based nationwide cohort study. Edited by JT Andersen. Epidemiol. Infect. 2013; 141: 1749-1755.

76. Gupta K, Hooton TM, Naber KG, et al: International clinical practice guidelines for the treatment of acute uncomplicated cystitis and pyelonephritis in women: A 2010 update by the Infectious Diseases Society of America and the European Society for Microbiology and Infectious Diseases. Clin. Infect. Dis. Off. Publ. Infect. Dis. Soc. Am. 2011; 52: e103-120.

77. Keating GM: Fosfomycin trometamol: a review of its use as a single-dose oral treatment for patients with acute lower urinary tract infections and pregnant women with asymptomatic bacteriuria. Drugs 2013; 73: 1951-1966.

78. Crider KS, Cleves MA, Reefhuis J, et al: Antibacterial medication use during pregnancy and risk of birth defects: National Birth Defects Prevention Study. Arch. Pediatr. Adolesc. Med. 2009; 163: 978-985.

79. Nicolle LE: Management of asymptomatic bacteriuria in pregnant women. Lancet Infect. Dis. 2015; 15: 1252-1254.

80. Yecies T, Bandari J, Fam M, et al: Risk of Radiation from Computerized Tomography Urography in the Evaluation of Asymptomatic Microscopic Hematuria. J. Urol. 2018; 200: 967-972.

81. Choudhary S: Deterministic and Stochastic Effects of Radiation. Cancer Ther. Oncol. Int. J. 2018; 12. Available at: https://juniperpublishers.com/ctoij/CTOIJ.MS.ID.555834.php, accessed October 9, 2019.

82. National Research Council (U.S.). Committee to Assess Health Risks from Exposure to Low Level of Ionizing Radiation: Health risks from exposure to low levels of ionizing radiation BEIR VII Phase 2. Washington, D.C.: Washington, D.C. : National Academies Press; 2006.

83. Harrison JD, Balonov M, Martin CJ, et al: Use of effective dose. Ann. ICRP 2016; 45: 215-224.

84. Stewart A and Kneale GW: Childhood cancer following obstetric radiography. Edited by A Stewart. Health Phys. 1973; 24: 359-359.

85. Stewart AM and Kneale GW: A-bomb survivors: Reassessment of the radiation hazard. Med. Confl. Surviv. 1999; 15: 47-56.

86. Jablon S and Kato H: Studies of the Mortality of A-Bomb Survivors: 5. Radiation Dose and Mortality, 1950-1970. Radiat. Res. 1972; 50: 649-698.

87. Preston DL, Cullings H, Suyama A, et al: Solid Cancer Incidence in Atomic Bomb Survivors Exposed In Utero or as Young Children. J. Natl. Cancer Inst. 2008; 100: 428436.

88. Anon: Committee Opinion No. 723: Guidelines for Diagnostic Imaging During Pregnancy and Lactation: Correction. Obstet. Gynecol. 2018; 132: 786-786.

89. Anon: ACR-SPR Practice parameter for imaging pregnant or potentially pregnant adolescents and women with ionizing radiation. Am. Coll. Radiol. 2018; Resolution 39. 
90. Streffer C, Shore R, Konermann G, et al: Biological effects after prenatal irradiation (embryo and fetus). A report of the International Commission on Radiological Protection. Ann. ICRP 2003; 33: 5-206.

91. White WM, Johnson EB, Zite NB, et al: Predictive value of current imaging modalities for the detection of urolithiasis during pregnancy: a multicenter, longitudinal study. J. Urol. 2013; 189: 931-934.

92. Hull AD and Moore TR: Multiple repeat cesareans and the threat of placenta accreta: incidence, diagnosis, management. Clin. Perinatol. 2011; 38: 285-296.

93. Baldwin HJ, Patterson JA, Nippita TA, et al: Maternal and neonatal outcomes following abnormally invasive placenta: a population-based record linkage study. Acta Obstet. Gynecol. Scand. 2017; 96: 1373-1381.

94. Ibrahim MA, Liu A, Dalpiaz A, et al: Urological Manifestations of Placenta Percreta. Curr. Urol. 2015; 8: 57-65.

95. Konijeti R, Rajfer J and Askari A: Placenta percreta and the urologist. Rev. Urol. 2009; 11: $173-176$.

96. Washecka $\mathrm{R}$ and Behling A: Urologic complications of placenta percreta invading the urinary bladder: a case report and review of the literature. Hawaii Med. J. 2002; 61: 6669.

97. Ng MK, Jack GS, Bolton DM, et al: Placenta percreta with urinary tract involvement: the case for a multidisciplinary approach. Urology 2009; 74: 778-782.

98. Russo M, Krenz EI, Hart SR, et al: Multidisciplinary approach to the management of placenta accreta. Ochsner J. 2011; 11: 84.

99. Eller AG, Porter TF, Soisson P, et al: Optimal management strategies for placenta accreta. BJOG Int. J. Obstet. Gynaecol. 2009; 116: 648-654.

100. Abbas F, Talati J, Wasti S, et al: Placenta percreta with bladder invasion as a cause of life threatening hemorrhage. J. Urol. 2000; 164: 1270-1274.

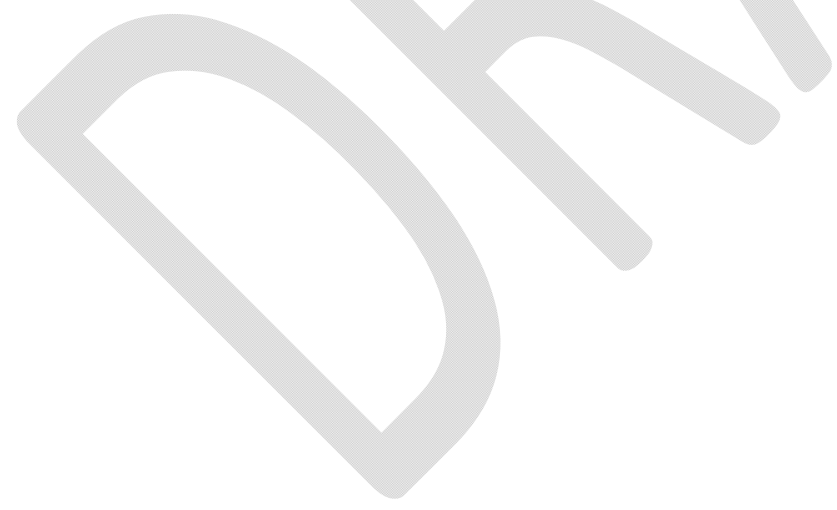


Figures and Tables

\begin{tabular}{|c|c|c|}
\hline Antibiotic & Dose & Duration \\
\hline Nitrofurantoin ${ }^{71}$ & 100 mg PO BID & $5-7$ days $^{\mathrm{a}, \mathrm{b}}$ \\
\hline Amoxicillin & $\begin{array}{l}500 \mathrm{mg} \text { PO TID } \\
875 \mathrm{mg} \text { PO BID }\end{array}$ & 5-7 days \\
\hline Amoxicillin-clavulanate & $\begin{array}{l}500 \mathrm{mg} \text { PO TID } \\
875 \mathrm{mg} \text { PO BID }\end{array}$ & 5-7 days \\
\hline Cephalexin & $250-500 \mathrm{mg}$ PO QID & 5-7 days \\
\hline Fosfomycin & $3 \mathrm{~g} \mathrm{PO}$ & One dose $\mathrm{e}^{\mathrm{b}}$ \\
\hline $\begin{array}{l}\text { Trimethoprim- } \\
\text { sulfamethoxazole }\end{array}$ & $800 / 160 \mathrm{mg}$ (DS) PO BID & 3 days $^{\mathrm{a}}$ \\
\hline
\end{tabular}

${ }^{a}$ Use should be avoided in the first trimester and at term if other options are available. ${ }^{b}$ Does not reach therapeutic levels in the kidney, avoid use if pyelonephritis suspected. 